Ш.И.Ониани, Т.О.Лацабидзе, О.А.Ланчава

\title{
ТЕМПЕРАТУРНОЕ ПОЛЕ ШАХТЫ № 8 ТКВАРЧЕЛЬСКОГО КАМЕННОУГОЛЬНОГО МЕСТОРОЖДЕНИЯ
}

Чрезвычайно сложные геоморфологические и геологические условия в рассматриваемом случае усугубляются еще особенностями, вызванными наличием термальных вод. Поэтому практически единственно приемлемым способом построения температурного поля шахты следует считать метод математического моделирования с использованием данных имеющихся шахтных наблюдений.

Минимальный возраст термальных вод составляет 1000000 лет, поэтому процесс рассеивания их тепловой энергии в горном массиве можно считать установившимся. В течение продолжительности существования шахты температура любой точки горного массива остается постоянной, т.е. естественное температурное поле шахты для данной задачи является стационарным. Поэтому искомое температурное поле шахты было построено методом электротепловой аналогии с применением интегратора ЭГДА - 9/60.

Методика электрического моделирования температурных и других потенциальных полей на интеграторе ЭГДА-9/60 подробно изложена в работах /1, 2/.

Здесь остановимся лишь на некоторых особенностях построения температурных полей месторождений с учетом влияния термальных вод Обычно построение потенциального поля на плоскости с источник тепла постоянной температуры при известных граничных условиях не представляет особой трудности. Но для этого необходимо иметь подробную характеристику источника тепла, как-то: температуру, форму и размеры источника, характер распределения потенциала внутри источника, распределение температуры в среде до начала процесса и условия теплообмена в особых местах системы. Большая часть перечисленных данных, необходимых для реализации подобия действия источника тепла, в данном случае отсутствует.

Степень влияния термальных вод на температурное поле шахты зависит ох их распространённости в пространстве .Это влияние максим мально у поверхности земли в районе выхода термальных источников. С увеличением глубины оно постепенно уменьшается и на какой-то определенной глубине совершенно исчезает. На этой глубине температура термальных вод равна первоначальной температуре горных пород. С этой глубины в сторону поверхности начинает сказываться влияние рассеивания тепла гидротерм и поэтому для моделирования необходимо ее достоверное определение. Глубина равных температур горных пород и хермальных вод определялась следующим образом. Естественная, невозмущенная термальными водами плотность глубинного теплового потока в районе движения горячих вод берется равной плотности потока для соответствующих условий (подразумевается одинаковость отметок, температур нейтрального слоя и структур стратиграфических разрезов) Ткибули-Шаорского каменноугольного месторождения, кохорая определяется по известным профилям геотемпературного поля месторождения /2/.

Зная плотность теплового потока и теплофизические свойства горных пород, 
составляющих стратиграфический разрез рассматриваемого района, строится геотермограмма толщи (ломаная линия 2, рис.1). Далее температура термальных вод в пределах 3-4-х км принимается однозначной функцией глубины и по данным термометрии горячих вод на разных горизонтах строится гермограмма термальных вод (прямая 1, рис.1). Точна пересечения этих термограмм (3125 м от поверхности, рис.1) представляет искомую глубину, нижнюю границу действия источника тепла. Таким образом, приближенным определением по гидрогеологическим данным области распространения восходящего движения термальных вод, нижней границы возможных возмущений температурного поля шахты и характера распределения температуры внутри источника, создается возможность электрического моделирования влияния источника тепла на распределение температуры в горном массиве шахты.

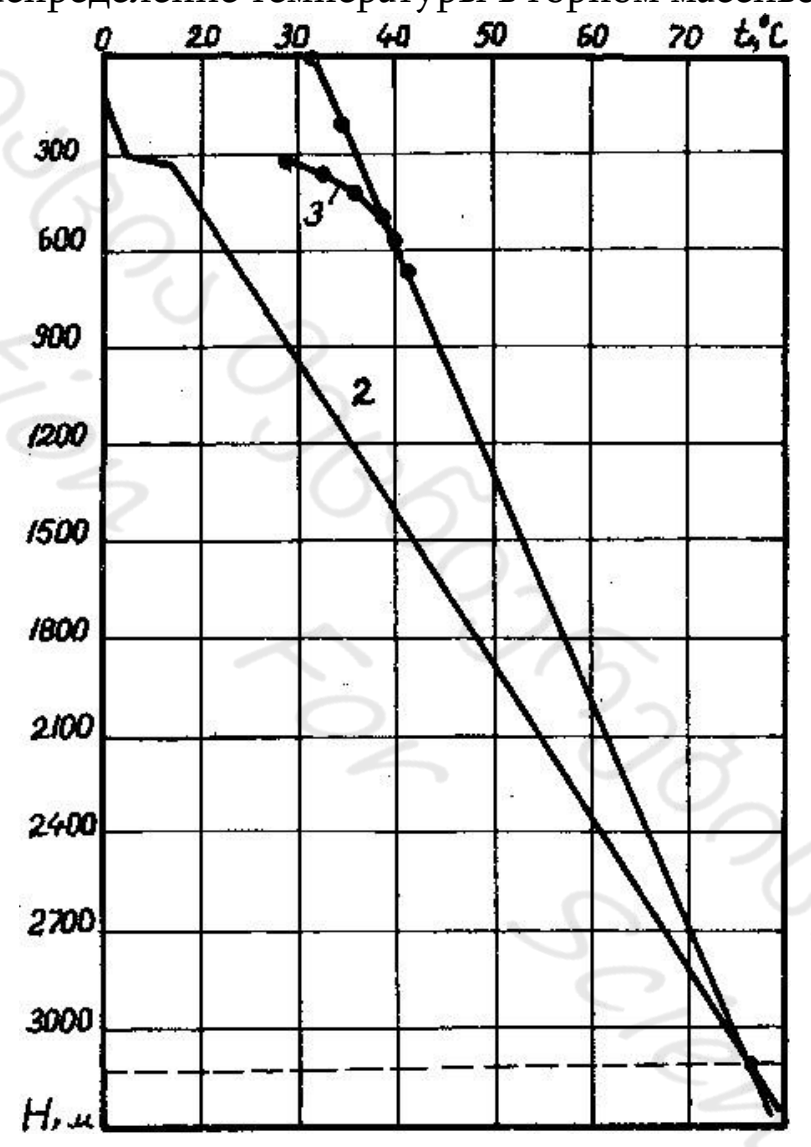

Рис. 1

Изменение температуры горных пород и термальных вод в зависимости от глубины: I термограмма термальных вод; 2 - термограмма горного массива без учета влияния термальных вод; 3 - реальная термограмма горного массива по стволу № 2.

Отклонение термограммы пород (рис.1), построенной по результатам термометрии в слепом стволе от термограммы термальных вод объясняется увеличением расстояния между основным каналом восходящего движения горячих вод и стволом с повышением отметки точки наблюдения.

Для моделирования температурного поля ІУ угленосной площади были выбраны 12 стратиграфических разрезов, из которых 4 находятся в районе восходящего движения термальных вод (рис.2).

Из электропроводных бумаг, вырезанных в соответствующем масштабе, 
изготовлялись модели отдельных свит литологических разностей. Путем склеивания этих моделей в нужной последовательности, строились полные аналоги стратиграфических рагрезов, ва которых осуществлялась реализация граничных условий, означенных в работе /2/, а также условия линейного изменения температуры термальных источников по глубине:

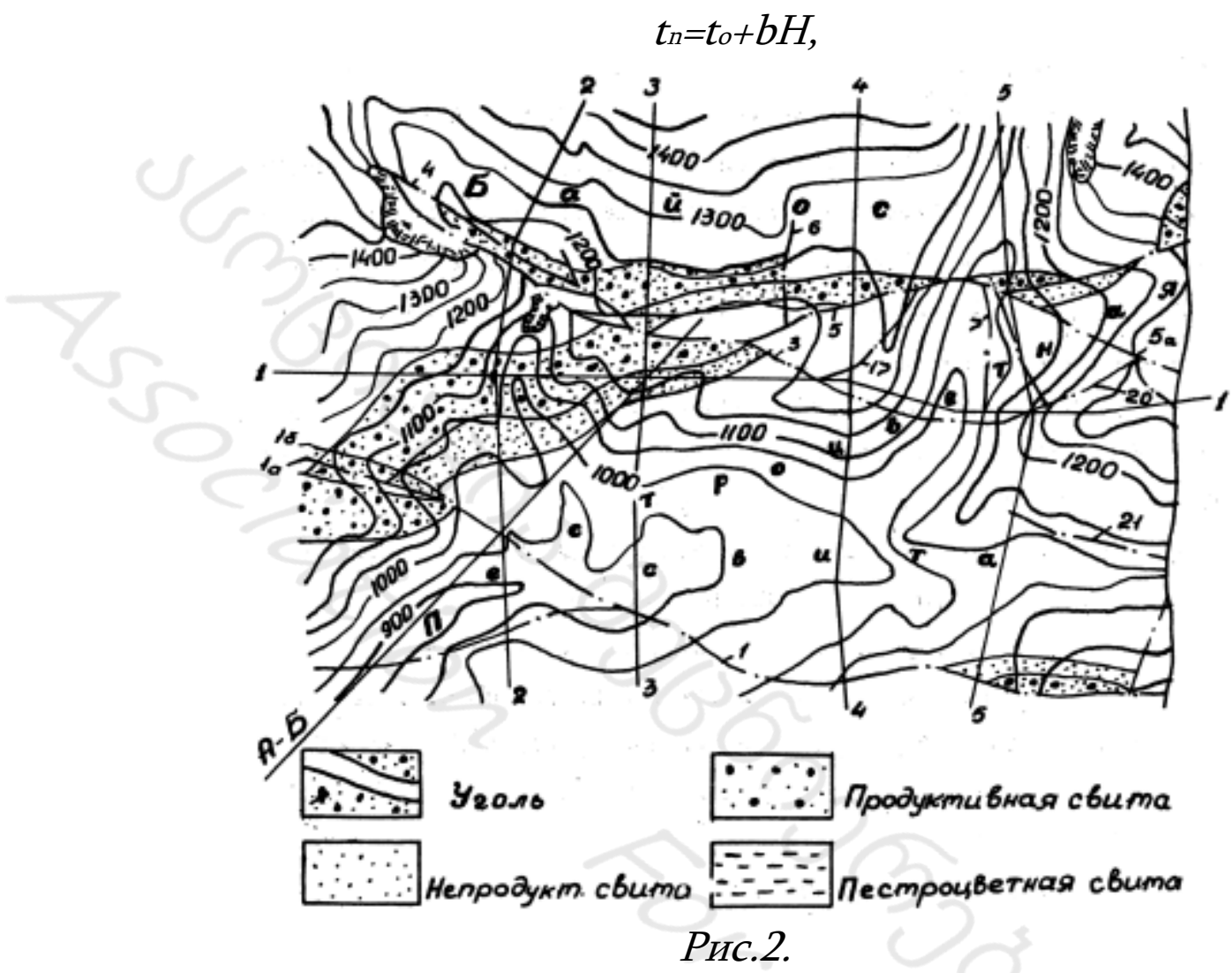

Геологическая карта IУ угленосной площади Ткварчельского каменноугольного месторождения

где $\mathrm{t}_{\mathrm{o}}=35$ - температура термальной воды на отметке 1100 м от уровня моря, ${ }^{\circ} \mathrm{C}$; $\mathrm{b}=0,017$ - коэффициент, характеризующий повышение температуры термальных вод при увеличении глубины на 1 м, град/м;

Н - глубина, м.

Реализация этого граничного условия осуществлялась с помощью шины из низкоомной электропроводной бумаги, которая специальным клеем приклеивалась к аналогу в районе восходящего движения термальных вод. В этой шине о помощью делителей напряжения интегратора создавалось падение потенциала, соответствующее распределению температуры в термальных водах по глубине.

Горный массив шахты неоднородный. Поэтому подбор электропроводной бумаги для моделирования такой неоднородной среды осуществлялся по соотношению

$$
\frac{\lambda n}{\lambda_{1}}=\frac{q_{n}}{g_{1}}
$$

где $\lambda_{1}$ и $\lambda_{n}$ - теплопроводности угольной толщи и n-ой области натуры, соответственно; $\mathrm{g}_{1}$ и $\mathrm{g}_{\mathrm{n}}$ - электропроводности бумаг, заменяющих угольную толщу и n-ую область в аналоге, соответственно. 
Результаты подбора электропроводной бумаги представлены в табл. 1, ив которой видно, что расхождение между реальными и смоделированными значениями теплопроводностей литологических разностей пород не превышает 3,5\%.

Ниже приводятся наиболее характерные пять разрезов, которые находятся в районе влияния термальных вод. Разрез А-Б проходит по вскрывающим штольням и слепым стволам № 1 и 2. Разрез 1-1 охватывает капитальные квершлаги, полевые штреки и слепые стволы № I и 2. Вое остальные разрезы охватывают бремсберги, уклоны и скаты (рис.2).

На рис. 2 представлена геологическая карта ІУ угленосной площади с нанесением направлений стратиграфических разрезов, характеризующих шахтное поле. Проявление основных термальных вод было зафиксировано при проходке поевого штрека гор. +950 м и капитальной штольни(гор. +500 м). По обоим местам излива термальных вод проходят разрезы А-Б, I-I и 3-3. Термальные источники на поверхности были зафиксированы между разрезами 2-2 и 3-3 около сброса № 3.

На рис. 3-6 приведены профили геотемпературного поля по 4-ом стратиграфическим разрезам. Глубина приложения нижней токозадающей шины на всех разрезах составляла 3500 и ниже уровня моря. На рисунках приведены только верхние участки профилей, так как тепловое состояние горного массива рассматриваемого шахтного поля ниже залегания угольной толщи в данном случае интереса не представляет. При моделировании расстояние от боковых контуров до выходов угольных пластов на поверхности составляло 7-1,5 ки (на рис.3-6 эти расстояния опущены с целью уменьшения размеров чертежей).

Переход от потенциальных полей аналогов к температурным полям разрезов и распределение относительных потенциалов по верхнему контуру осуществлялась по величинам температур в точках $\mathrm{K}_{1}$ и $\mathrm{K}_{2}$ (рис.3 и 4), определенных путем непосредственных измерений температур пород при проходке штольни.

На рис.7 представлена термогипсометрическая карта почвы угольной толщи (I пласт) в пределах ІУ угленосной площади. Карта построена путем интерполяции данных всех двенадцати профилей температурных полей. 
Результаты подбора электропроводных бумаг

\begin{tabular}{|c|c|c|c|c|c|c|c|c|}
\hline $\begin{array}{r}\text { № } \\
\text { № } \\
\text { ПП }\end{array}$ & Наименование пород & $\begin{array}{l}\text { Теплопровод } \\
\text { ность, } \\
\text { вт/м.град. }\end{array}$ & $\begin{array}{l}\text { Термическое } \\
\text { сопротивление } \\
R, \text { м.град/ва }\end{array}$ & $\begin{array}{l}\text { Расчетное } \\
\text { сопротив } \\
\text { ление } \\
\text { бумаги } \\
\mathrm{R}_{\text {o.ком }}\end{array}$ & $\begin{array}{l}\text { Количество и } \\
\text { сопротивле- } \\
\text { ние бумаги } \\
\mathrm{R}_{\text {о.,ком }}\end{array}$ & $\begin{array}{l}\text { Фактичес- } \\
\text { кое соп- } \\
\text { ротивление } \\
\text { бумаги } \\
\mathrm{R}_{\text {o.ком }}\end{array}$ & $\begin{array}{l}\text { Смодели } \\
\text { рованная } \\
\text { теплопро } \\
\text { водность } \\
\lambda, \text { вт/ } \\
\text { м.град }\end{array}$ & $\begin{array}{c}\text { Погрешность } \\
\text { подборабумаги, } \\
\% \%\end{array}$ \\
\hline 1. & Четвертичные отложения & 1,00 & 1,00 & 38,2 & $3 \times 114$ & 38 & 1,00 & 0,0 \\
\hline 2. & Пестроцветная свита & 1,92 & 0,52 & 19,8 & 19,6 & 19,6 & 1,90 & 1,0 \\
\hline 3. & Непродуктивная свита & 2,09 & 0,48 & 18,3 & 18,9 & 18,9 & 2,16 & 3,3 \\
\hline 4. & Песчаник угленосной свиты & 2,86 & 0,35 & 13,4 & 13,5 & 13,5 & 2,88 & 0,7 \\
\hline 5 . & Угольная толща(при $\gamma=1300$ & 0,25 & 4,35 & 166 & 166 & 166 & 0,23 & 0,0 \\
\hline 6. & Песчаники байоса & 2,24 & 0,45 & 17,1 & 17,7 & 17,7 & 2,32 & 3,5 \\
\hline
\end{tabular}




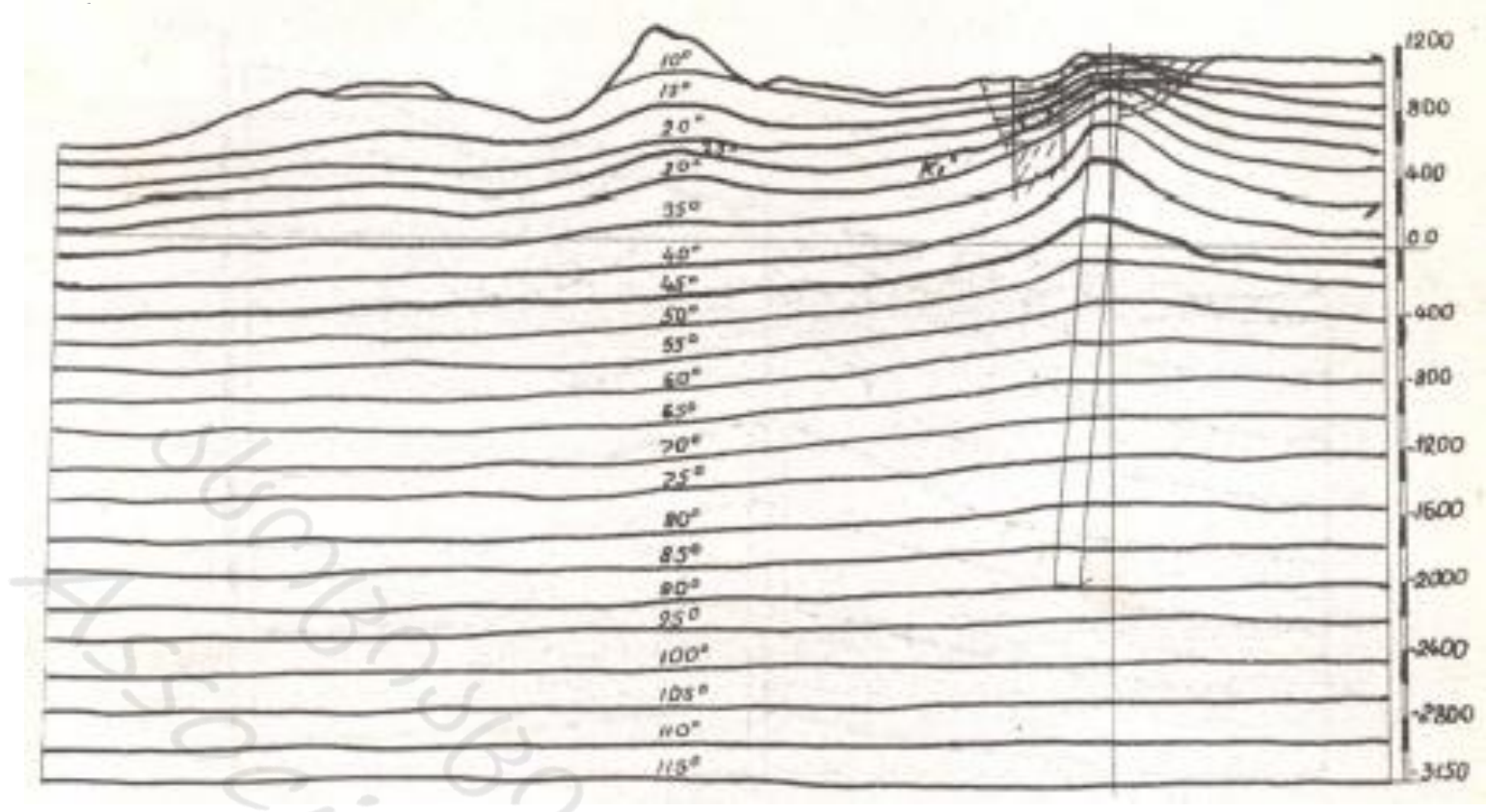

Рис.3. Профиль геотемпературного поля по разрезу А-Б

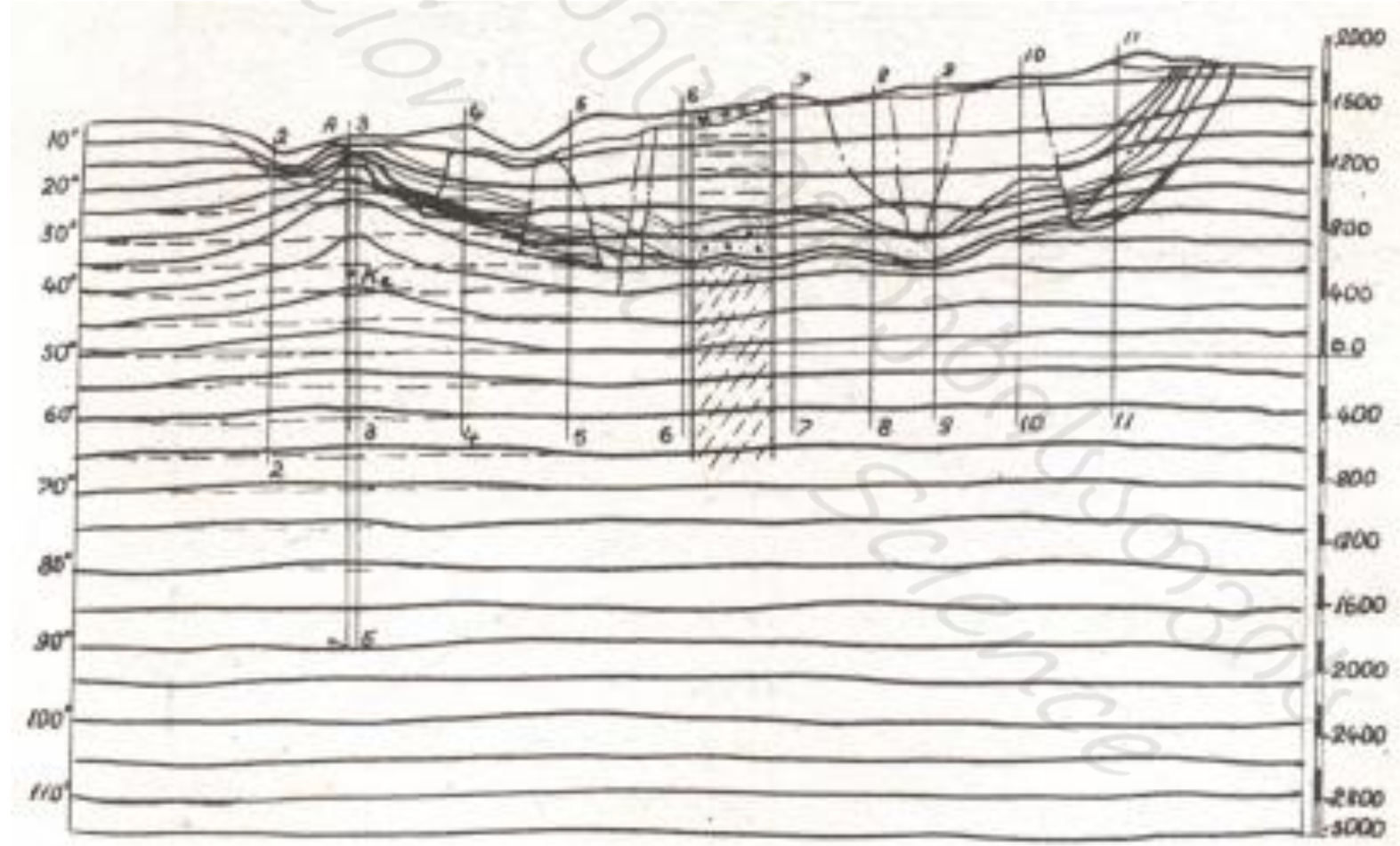

Рис.4. Профиль геотемпературного поля по разрезу I-I

ГОРНАЯ ЭЛЕКТРОМЕХАНИКА И РУДНИЧНАЯ АЭРОЛОГИЯ. ИЗДАТЕЛЬСТВО «МЕЦНИЕРЕБА» 


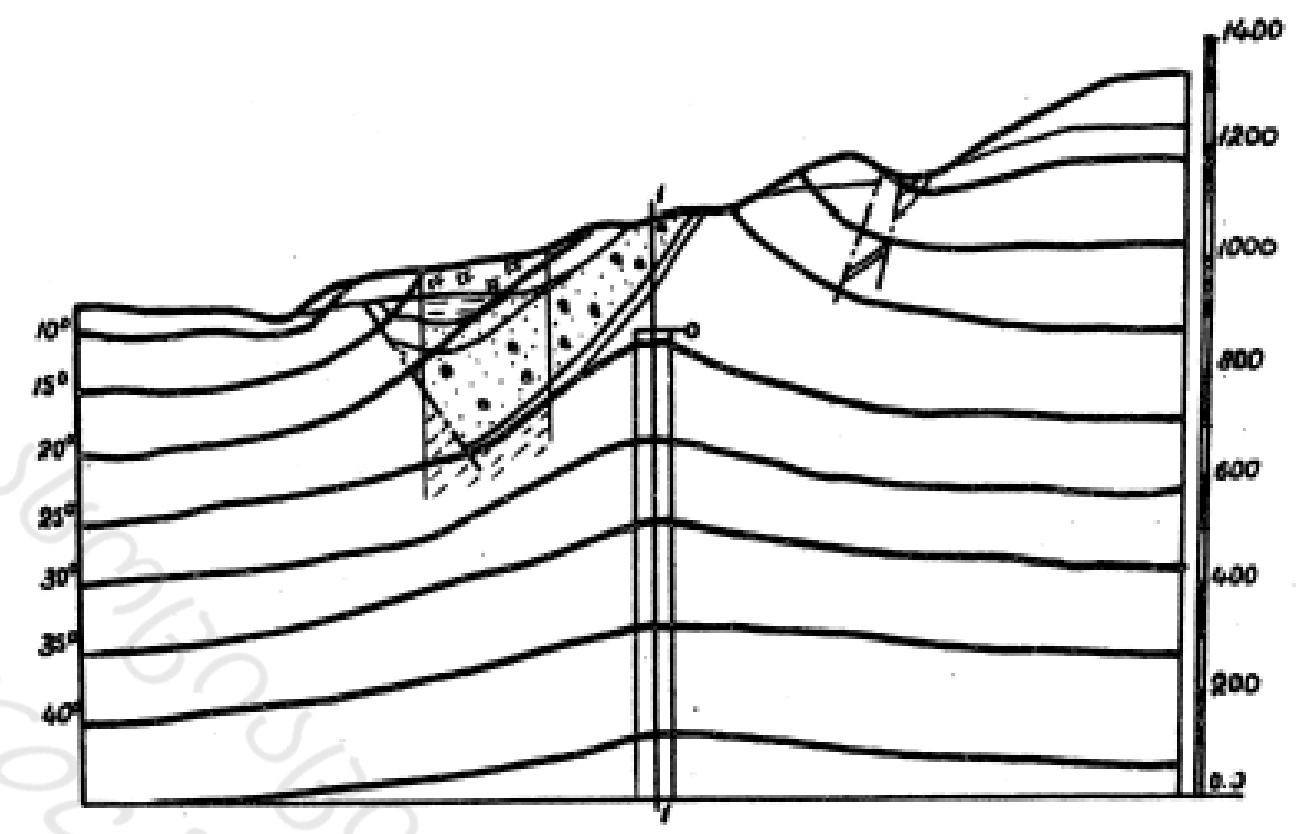

Рис.5. Профиль геотемпературного поля по разрезу П-П

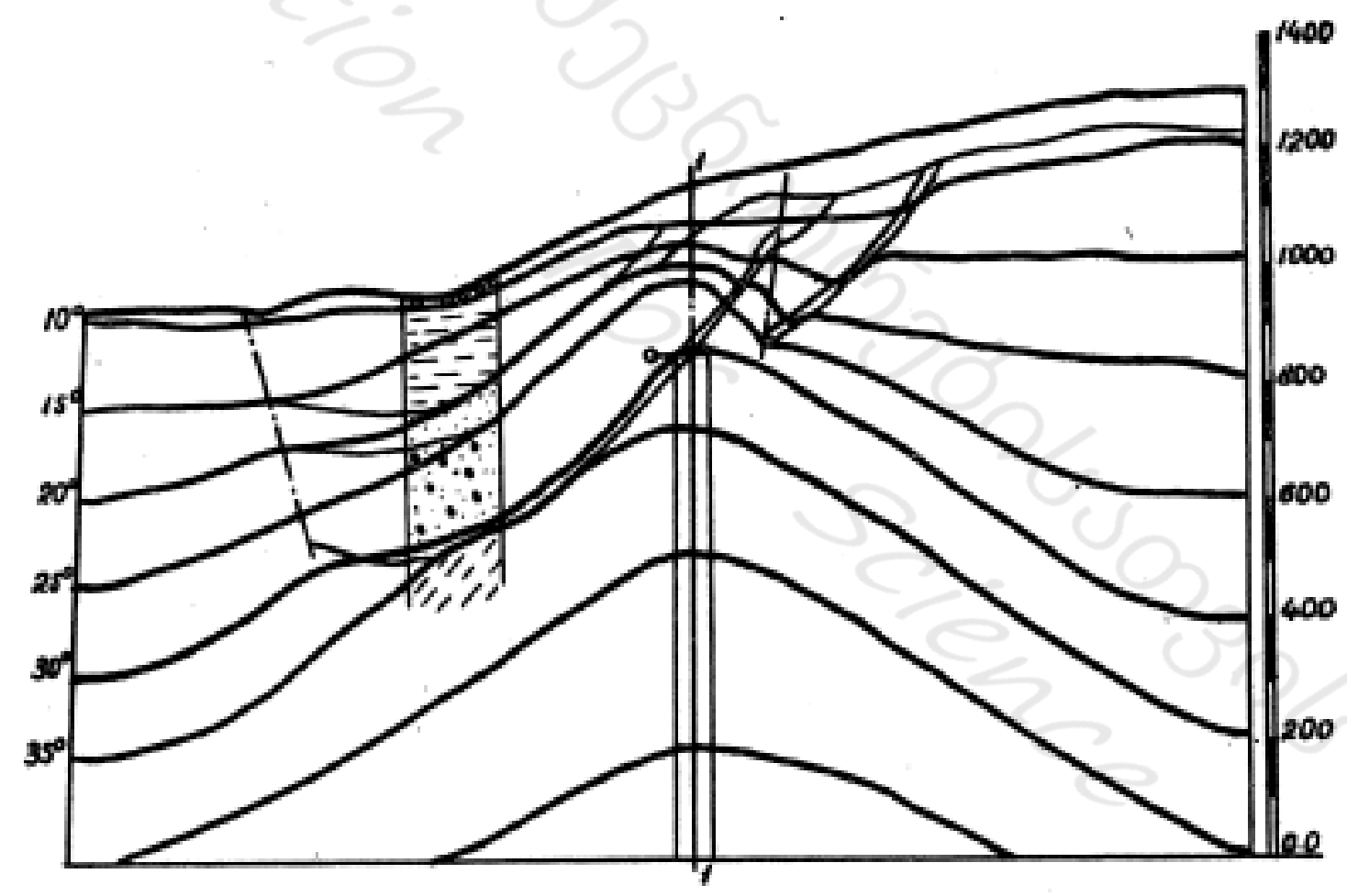

Рис.6. Профиль геотемперагурного поля по разрезу Ш-Ш 


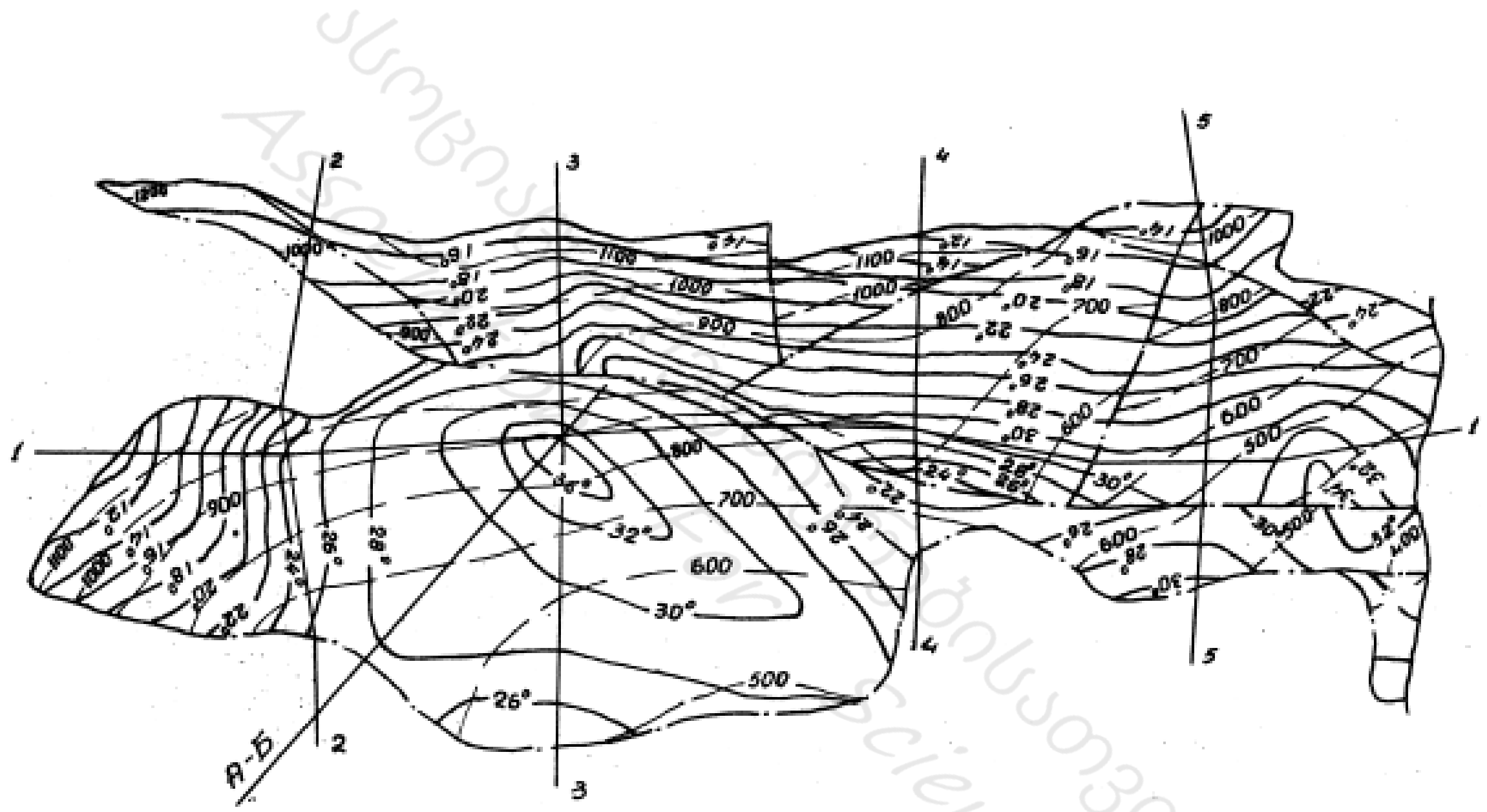

Рис. 7. Термогипсометрическая карта почвы пласта 1 
Анализ полученных результатов моделирования показывает, что термальные воды существенно возмущают естественное температурное поле шахты. Искажения температурного поля максимального значения достигают в местах выхода горячих вод на поверхности и в зависимости от конкретных условий составляют 12-20 град. С увеличением глубины, вследствие снижения первоначальной разности температур между источником и средой, возмущения теплового поля постепенно уменьшаются и на глубине 1600-2000 м от поверхности практически исчезают.

Область распространения температурных возмущений вдоль горизонтальной плоскости не превышает 4-5 км.

Возмущения температурного поля, вызванные восходящим движением горячих вод, распространяются на весь западный участок шахты. Восточнее сброса № 8 прямое влияние термальных вод отсутствует, однако повышение плотности теплового потока на западном участке косвенно предопределяет некоторое уплотнение теплового потока и на восточном участке и тем самым повышение потенциала температурного поля этого района. Вдоль капитальных полевых штреков гор. + 500 м температура горных пород колеблется в пределах $37-43^{\circ} \mathrm{C}$, на гор. +750 м температура не превышает $39^{\circ} \mathrm{C}$, в северном направлении она постепенно снижается и на границе западного участка составляет 32$33^{\circ} \mathrm{C}$.

О характере распределения температуры, по падению угольных пластов ясное представление дают профили геотемпературного поля. Распределение потенциала внутри источников тепла на пис.5 определялось по соответствующим данным рис.3. Во всех поперечных профилях температурного поля шахты, независимо от степени возмущенности теплового состояния, хорошо прослеживается влияние формы залегания неоднородных и анизотропных пород. Например, несмотря на действие довольно сильного источника тепла на рис.6, изотермы 30 и $35^{\circ} \mathrm{C}$ как бы притягиваются угольной толщей, на значительном расстоянии следуют по ней и принимают форму ее залегания. То же самое наблюдается и на других профилях.

Рассмотрение термогипсометрической карты ${ }^{\mathrm{x})}$ показывает, что в районе движения термальных вод на горизонтах $+700-+800$ м температура по почве пласта I достигает $32-34^{\circ} \mathrm{C}$. За сбросом № 8 температура угля на горизонтах $+300-+400$ м составляет $34-36^{\circ} \mathrm{C}$. Изотерма $36^{\circ} \mathrm{C}$ начинается от сброса № 8 и прослеживается почти до конца шахтного поля. Примерно по всей глубине стратиграфических разрезов главным фактором, предопределяющим распределение температуры в породном массиве восточного участка, являются теплофизические свойства и форма залегания пород, а также тектонические нарушения.

Влияние рельефа поверхности имеет подчиненное значение. 
Электротепловые аналоги отдельных стратиграфических разрезов по вертикальным линиям пересечения дают одинаковое распределение температуры с глубиной (одноименные изотермы разных профилей на линиях пересечения имеют одинаковую глубину залегания от поверхности).

Таким образом, приведенные на рис.3-7 денные, дающие достаточно полную и точную картину теплового состояния пласта I (по почве) и подстилающих пород, по которым будут проведены подготовительные выработки, указывают на то, что на нижних горизонтах шахты № 8 следует ожидать ненормальные тепловые атмосферные условия.

Следовательно, поргноз и регулирование теплового режима этих горизонтов следует очитать неотложной задачей горной науки и техники Грузии.

\section{Литература}

1. П.Ф.Фильчаков, В.И.Панчишин. Интеграторы ЭГДА. Изд-во АН УССР, Киев, 1961.

2. А.А.Дзидзигури, Ш.И.Оннани, Т.О.Лацабидзе. Вопросы геотермии ТкибулиШаорокого каменноугольного месторождения. "Мецниереба", Тбилиси, 1967.

х) На рис.7 она дана только для западного участка. 